\title{
THE ADAPTATION OF INTERNET ADDICTION SCALE INTO TURKISH: THE STUDY OF VALIDITY AND RELIABILITY
}

\begin{abstract}
Murat KAYR'ं*
Selim GÜNÜÇ**

Abstract. It has been noticed that internet addiction scale which can apply and measure dependency level of individual couldn't reach at saturation level in national literature. So, it was aimed to adapt an internet addiction scale. Adapted scale was developed by Nichols and Nicki in 2004 and this study was sounded as "Internet Addiction Scale". The reliability cronbach alfa of original scale was obtained as .95 by Nichols and Nicki. In adapting study, cronbach alfa value was obtained as .93 . The sample has been constituted from 277 students who belong to Yuzuncu Yil University and who visits periodically Computer Sciences Researches and Application Centre for surfing internet application. In this study, exploratory factor analysis was used to determine the validity of scale and after, confirmatory factor analysis was handled to test the fitness of the model. The main aim of this study is to adapt Internet Addiction Scale. Besides, the dependency level of sample was examined. According to the results, 32 people are consisted of the addiction risk group. As a result, the validity and the reliability findings are in optimal values which literature has been declared.
\end{abstract}

Key Words: Internet addiction, scale adapting, factor analysis.

\footnotetext{
* Assist. Prof. Dr., Yuzuncu Y11 University, Faculty of Education, mkayri@yyu.edu.tr,

${ }^{* * *}$ Res. Assist., Yuzuncu Y1l University, Faculty of Education, selimgunuc@ yyu.edu.tr,
} 


\section{SUMMARY}

Purpose and Significance: The aim of this study is to introduce internet addiction concept and to adapt an internet addiction scale. Examining Turkish literature, lacking of internet addiction scale will be noticed. So, it is necessary to develop or adapt a coherent, objective and robust scale. All kinds of addiction may effect people negatively, and especially students because of education. It is too crucial to determine some issues which effect on individual's education. Also it is worth to examine which factors are influential on both education and individual development. In this century, one of the most important factors is internet addiction which can effect on the whole life of people. Extremely using internet may lead an addiction which can be a pathologic illness. The literatures consider that internet addiction is both pathologic and spiritual matters. Because of all above reasons, it will provide so benefits to determine "is there any dependency on people", after answering this; the other important issue is to measure "what is the level of dependency". The purpose of this study is to search both national and international literatures, and the main goal of this research is to adapt an internet addiction scale which is developed in recent time by Nichi and Nichols.

Methods: To adapt Nichols and Nichi's Internet Addiction Scale (IAS), firstly, the all items of the scale was translated into Turkish by three experts. After translating, 10 students had been read and it was queried "is translation clear or not?". All students agreed with the clarity of the translated scale. IAS is consisted of 31 items. The cronbach alfa of IAS is 0.95 and the explained variance is $46.50 \%$. IAS which is developed by Nichols and Nichi was handled on 233 college students and the researchers intend to develop a scale and measure level of internet dependency. The IAS should be scored by adding Likert responses across the 31 items. They suggest a cutoff score of 93 ( $3 * 31$ items) as indicative of possible internet addiction. In adapting study, cronbach alfa value was obtained as 0.93 . The sample has been constituted from 277 students who belongs to Yuzuncu Yil University and who visits periodically Computer Sciences Researches and Application Centre for surfing internet application.

In this study, exploratory factor analysis was used to determine the validity of scale and after, confirmatory factor analysis was handled to test the fitness of the model. SPSS and Lisrel software are used for both exploratory and confirmatory factor analyses. 
Results: According to finding of exploratory factor analysis, similar to original scale, adapting scale was resulted in one dimension with $33.295 \%$ explained variance. Also, Kaiser-Meyer-Olkin (KMO) and Barlett test confirm the appropriateness sample size with .93 value $\left(X^{2}=3103.332\right.$; $\mathrm{p} \cong .000$ ). Although the original scale had 31 items, in adapting scale, 30 item numbers were obtained by exploratory factor analysis. Fit of obtained model was carried out by confirmatory analysis and the findings were in acceptable borders. Root Mean Square Error of Approximation (RMSEA) is .075 value that the optimal RMSEA is between .05 and .08. Comparative Fit Index (CFI) is an indicator of a goodness model and the result of GFI is .79. The other indicator which is Goodness of Fit Index (GFI) value is .74. All goodness of fit indexes show that obtained validity scale can be accepted in one dimension.

Discussion and Conclusions: The main aim of this study was to adapt Internet Addiction Scale. Besides, the dependency level of sample was examined. According to the results, 32 people are consisted of the addiction risk group. As a result, the validity and the reliability findings are in optimal borders which literature has been declared. 


\section{INNTERNET BAĞIMLILIK ÖLÇEĞINIIN TÜRKÇEYE UYARLANMASI: GEÇERLİK VE GÜVENİRLIIK ÇALIŞMASI

\author{
Murat KAYRi“* \\ Selim GÜNÜÇ***
}

Öz. Temelde bireyin internet başında uzun süre kalmasını ifade eden internet bağımlılığının tespitine yönelik, ulusal alanyazında yeterli sayıda ölçeğin bulunmaması bu alanda ölçme aracı geliştirme ya da uyarlama ihtiyacını doğurmuştur. Bu çalışmada, Nichols ve Nicki'nin (2004) geliştirmiş oldukları 'Internet Bağımlılık Ölçeği'nin (Internet Addiction Scale) Türkçeye uyarlanıp, yapı geçerliğini ve iç tutarlılık güvenirlik katsayısını belirlemeye yönelik bir araştırma yapılmıştır. Nichols ve Nicki (2004) ölçeğin özgün formuna ilişkin iç tutarlılık katsayısını (cronbach alfa) .95 olarak tespit etmiştir. Bu uyarlama çalışması örneklemini, seçkisiz örnekleme metodu ile Yüzüncü Y1l Üniversitesi Bilgisayar Bilimleri Araştırma ve Uygulama Merkezi'nde (BBAUM) bilgisayar laboratuarını kullanan 277 ögrenci oluşturmakta olup, uyarlama ölçeğine ilişkin güvenirlik katsayısı da (cronbach alfa) .93 olarak tespit edilmiştir. Bu çalışmada, yapı geçerliği için açımlayıcı (exploratory) faktör analizi, elde edilen faktör yapısının doğruluğunu test etmek için de doğrulayıcı (confirmatory) faktör analizi kullanılmıştır. Ölçek uyarlamasıyla birlikte çalışma grubundaki bağımlılık düzeyleri de incelenmiş ve 32 bireyin internet bağımlısı olma yolunda risk içerisinde oldukları belirlenmiş̧tir. Ayrıca internet bağımlılık ölçeğinin Türkçe uyarlamasına yönelik yapılan geçerlik - güvenirlik analizleri, alanyazın ışığında değerlendirilmiş ve elde edilen değerlerin beklenen sinırlar içerisinde olduğu görülmüştür.

Anahtar Sözcükler: İnternet bağımlılı̆̆ı, ölçek uyarlama, faktör analizi.

\footnotetext{
*Yrd. Doç. Dr., Yüzüncü Yıl Üniversitesi, Eğitim Fakültesi, BÖTE Bölümü, mkayri@yyu.edu.tr

*** Araş. Gör., Yüzüncü Yıl Üniversitesi, Eğitim Fakültesi, BÖTE Bölümü, selimgunuc@yyu.edu.tr
} 


\section{GİRIS}

Yaşanılan yüzyılda, televizyon, cep telefonu ve bilgisayar teknolojileri insan yaşamında önemli bir yer edinmiş olup, bu gelişimini hızlı bir șekilde sürdürmektedir. Özellikle son yıllarda, bilgisayarın ayrılmaz bir öğesi haline gelen internet teknolojileri günlük yaşamda sık kullanılan teknolojiler arasında yerini almıştır. İnternet teknolojisinin bu denli hızlı gelişimi ve insan yaşamında önemli bir yere sahip olmasının bazı nedenleri bulunmaktadır. Bunlar arasında; internetin farklı kültürlerden farklı toplumlara ulaşan ve tüm dünyayı saran kolay erişilebilir bir ağ olması, farklı yaş gruplarına ve birçok farklı amaca yönelik kullanılabilmesi gibi etkenler düşünülebilir. Ayrıca internetin iletişim, haber, bilgi, oyun vb. unsurları bünyesinde barındırarak insan yaşamını kolaylaştırması ve zaman tasarrufu sağlamasının yanında eğlence ve zevk amacı taşıyan geniş bir kullanım alanına sahip olması insan yaşamı için önemli görülmektedir. Toplumların, ucuz ve hızlı internet erişimi sağlama yönünde gelişme göstermesi, internet kullanım oranında artışa neden olmaktadır. Ancak, internetin her geçen gün kolay erişilebiliyor olması, farklı amaç ve olanaklar sunmas1, bireyin internet başında geçirdiği zamanı artırabilmekte, ancak bununla birlikte bir takım zihinsel ve fiziksel olumsuzluklara neden olabilmektedir (Murali ve George, 2007).

Bireyin, internet başında uzun zaman harcamasından ötürü bireyde kas, göz ve baş ağrıları gibi bir takım fiziksel problemlerin dışında, aşırı internet kullanımının bağımlılığa dönüşmesiyle kaygı, üzüntü, depresyon, hoşgörü eksikliği gibi (Zsolt ve diğ., 2008) zihinsel problemler de bireyleri etkileyebilmektedir. $\mathrm{Bu}$ problemler, araştırmacılar tarafindan benzer kavramlarla açıklanmaya çalışılmaktadır. Bunlar arasında; "internet addiction (internet tutkusu)" (Young ve Rodgers, 1998), "internet dependency (internet bağımlılı̆̆ 1 )" (Tvedt, 2007), "pathological internet use (patolojik internet kullanımı)" (Young, 2004), "problematic internet use (sorunlu internet kullanımı)" (Kaltiala-Heino ve diğ., 2004), "internet abuse (internet istismas1)" (Young ve Case, 2004), "cyberaddiction (siber tutku)" (Vaugeois, 2006) vb. kavramlar bulunmaktadır. Ulusal alanyazında ise daha çok internet bağımlılığı ve patolojik internet kullanımı kavramlarına yönelik araştırmalar yapılmış olup (Gönül, 2002; Bölükbaş, 2003; Odabaşığlu ve diğ., 2007), bu araştırmalar henüz doyurucu bir noktaya gelememiştir.

Olumsuz bir durumu ifade eden bağımlılık kavramı, bir madde ya da davranışı kullanmayı bırakamama veya kontrol edememe şeklinde tanımlanabilmektedir (Egger ve Rauterberg, 1996). Madde bağımlılı̆̆ 1 , kişinin aldığı alkol, ilaç, uyuşturucu gibi maddeleri yaşamında vazgeçilmez bir hale getirmesidir. Bireyler sadece bir maddeye değil, aynı zamanda problemli bir davranışa da bağımlı olabilirler. Fiziksel bir maddeye 
dayandırılamayan bağımlılıklar, davranış tabanlı bağımlılıklar olarak sınıflandırılabilir. Bunlar arasında; yeme bağımlılığı, oyun bağımlılığı, bilgisayar bağımlılığı, televizyon bağımlılı̆̆ı, alışveriş bağımlılığı, internet bağımlılığ gibi davranışlar örnek olarak gösterilebilir (Kim ve Kim, 2002).

İnternet bağımlılı̆̆ başlanmış ve temelde, internet başında uzun zaman geçirmeyi ifade etmektedir (Simkova ve Cincera, 2004; Leung, 2004; Yellowlees ve Marks, 2007). İnternet bağımlılığı sigara ve alkol bağımlılığı gibi bir bağımlılık türü olarak ele alınmış ve madde bağımlılığına benzer bir tedavi yaklaşımı içermektedir (Hall ve Parsons, 2001). Fiziksel madde bağımlılığına sahip bireylerde gözlenen sosyal olmayan davranışlar (Çöpür ve diğ, 1995), kendini internet bağımlılığında da gösterebilmektedir. Ayrıca, internetin yanlış kullanımı, internet bağımlılığına yol açabileceği gibi; seks, kumar, alışveriş vb. internet haricindeki diğer davranış bağımlılıklarını besleyici bir rol üstlenebilir (Bölükbaş, 2003).

İnternet bağımlılı̆ğıa farklı kültürlerde rastlanmakla birlikte (Cao ve $\mathrm{Su}, 2007)$, en fazla risk altında bulunan grup ergenler olarak belirtilmiştir (Şendağ ve Odabaş1, 2007; Mossbarger, 2008; Yen ve diğ., 2008). Öğrenciler, okullarda aldığı eğitim paralelinde çoğu zaman destek amaçlı ve özellikle zengin bilgi kaynağı sunması nedeniyle teknoloji araçlarına ihtiyaç duymakta olup (Şendağ ve Odabaşı, 2007), toplumun amaçları arasında da bireylerin teknoloji becerilerini kazanmaları beklenmekte ve eğitim ortamları da buna göre düzenlenmektedir. Öğrencilerin internet teknolojileri ile iç içe bulunmaları, olumlu sonuçların yanında patolojik internet kullanımı gibi istenmeyen durumların da oluşmasına yol açabilmektedir (Nalwa ve Anand, 2003). Bundan ötürü, özellikle ergen bireylerin ev, okul ve internet kafe ortamlarındaki internet kullanımları, bağımlılığın oluşumuna alt yapı oluşturabilmektedir (Lim ve diğ., 2004). Oluşan bağımlılı̆̆ın bir yansıması olarak, ergen bireyler, aile ortamında ebeveynleri ile sorunlar yaşamakta ve aile ilişkileri bozulabilmektedir (Esen, 2007; Şendağ ve Odabaşı, 2007). Bu bağlamda, ergenlerin internet kullanımları kontrol altında tutulmadığı takdirde bu teknoloji, bireyin okulda başarısız olmasına, derslerini kaçırmasına, sınavlara girmemesine ve sınavlarda başarısız olmasına yol açabilmektedir (Young ve Case, 2004; Young, 2004).

$\mathrm{Bu}$ çalışmada, bireylerdeki internet bağımlılığının varlığı ve bağımlılık düzeylerini belirlemeyi hedefleyen bir ölçme aracının Türkçe uyarlaması amaçlanmaktadır. Davranış bilimlerinde ölçmeye ve araştırmalara konu olan ve bu nedenle gereğince ölçülmesi gereken psikolojik değişkenlerden biri de tutumdur (Tezbaşaran, 1997). Bireylerin belirli nesneler karşısında sergilemiş oldukları olumlu / olumsuz tutumları inceleyen araçlardan biri de ölçeklerdir. Türkçe uyarlaması yapılan bu ölçek için uygun istatistiksel yöntemler belirlenmeye çalışılmıştır. 


\section{YÖNTEM}

\section{Araç}

Bu çalışma, Nichols ve Nicki' nin (2004) geliştirmiş oldukları İnternet Bağımlılık Ölçeği’nin (Internet Addiction Scale) Türkçeye uyarlanıp, yapı geçerliğini ve iç tutarlılık güvenirlik katsayısını belirlemeye yönelik bir araştırmadır. Nichols ve Nicki (2004) tarafından geliştirilen İnternet Bağımlılık Ölçeği (İBÖ), Temel Bileşenler Analiz (Principle-Component Analysis) yöntemi ile tek faktör altında toplanan 31 maddeden oluşmaktadır. Ölçeğin orijinaline ilişkin iç tutarlılık katsayısı (cronbach alfa) .95 ve ölçeğe ilişkin açıklanan varyans \%46.50 olarak tespit edilmiştir. Söz konusu özgün ölçek, 233 lisans öğrencisine uygulanmış ve bireylerin internet bağımlılık düzeylerini belirlemeyi hedeflemektedir. Ölçeğe ilişkin maddelerin tümü olumlu olup, beşli likert dereceleme ile ölçeklenmiştir. Likert formundaki tutumlar "1- Asla 2- Nadiren 3-Bazen 4-S1klıkla ve 5- Her zaman" şeklinde derecelendirilmiştir. Nichols ve Nicki (2004), ölçek maddelerinden elde edilen toplam puanın $93(3 * 31)$ ve üstü olma durumunu internet bağımlılı̆̆ının bir göstergesi olabileceğini savunmuşlardır. Hesaplamada geçen 3 değeri, likert sıralamadaki "bazen" tutum seviyesine karşl1ık gelmektedir. Bu anlamda, ölçeğe ilişkin eşik değer, likert derecelemedeki orta tutum seviyesine denk gelmektedir. Ölçekteki maddelerin toplam puanı 31 ile 155 arasında değişkenlik göstermekte olup, taban bağımlılık (cut-off) puanı 93 olarak bildirilmiştir.

İngilizce olan 31 maddelik özgün ölçek, üç uzman tarafindan Türkçeye çevrilmiş ve bu çeviriler anlamsal, kavramsal, deyimsel ve deneyimsel ölçütleri açısından karşılaştırılmıştır. Belirtilen ölçütler doğrultusunda üç çevirinin de tutarlı olduğu tespit edilmiş, ancak anlaşılabilirlik açısından en sade olan ifadeler tercih edilmiştir. Türkçe çevirinin tamamlanmasından sonra ölçeğin 31 maddesi 10 öğrenciye okutulmuş ve maddelerin anlaşılabilirliği öğrenciler tarafindan da onaylanmıştır.

\section{Örneklem}

Çalışmanın evrenini, Yüzüncü Yıl Üniversitesi (YYÜ) öğrencileri oluşturmakta olup, YYÜ Bilgisayar Bilimleri Araştırma ve Uygulama Merkezi'ne (BBAUM) rassal olarak bilgisayar kullanım amaçlı gelen 277 öğrenci örneklem olarak alınmıştır. Örnekleme alınan 277 öğrenciden \% 45'i 17-19 yaş aralığ 1 , \% 44,4 ile 20-22 yaş, \% 8,3 oranı ile $23-25, \% 1,1$ 'ini de 26-28 yaş aralığında olduğu tespit edilmiştir. Bu durumda yaş sıklığının 1722 aralığında olduğu kabul edilebilir. Ölçek 277 lisans öğrencisine uygulanmasına rağmen 24 bireyin ölçek maddelerini sağlıklı cevaplamadığı tespit edilmiş olup, söz konusu 24 birey veri setinden çıkarılmıştır. Dolayısı 
ile ölçek uyarlama çalışması 253 bireyin maddelere vermiş oldukları cevaplar üzerinden yürütülmüştür. Uyarlama çalışmasındaki 253 öğrencinin 215'i (\%85) erkek ve 38'i (\%15) kız olarak tespit edilmiştir. Ayrıca, ölçeğin Türkçe uyarlaması için etik ve nezaket açısından gerekli izinler ölçeğin gerçek sahipleri olan Nichols ve Nicki' ye elektronik posta yolu ile bildirilmiştir ve yazarlardan oldukça memnuniyet verici dönütler alınmıştır. Benzer şekilde, ölçek yapısındaki gerekli değişiklikler için de ilgili yazarlardan tavsiyeler alınmıştır.

\section{İşlem ve Veri Analizi}

Ölçeğe ilişkin uyarlama çalışmasında yapı geçerliği için açımlayıcı (exploratory) faktör analizi, elde edilen faktör yapısının doğruluğunu test etmek için de doğrulayıcı (confirmatory) faktör analizi yöntem olarak belirlenmiştir. Açımlayıcı faktör analizinde temel bileşenler analiz yöntemi, doğrulayıcı faktör analizinde ise maksimum olabilirlik yöntemi esas olarak alınmıştır. Ölçeğin güvenirliği için de iç tutarlılık katsayısını elde etmeye hedefleyen Cronbach alfa değeri ölçüt olarak değerlendirilmiştir.

Ölçeklerin geçerlik-güvenirlik çalışmaları için kullanılan istatistiksel yöntemlerden biri faktör analizi olarak bilinmektedir. Faktör analizi, birbiriyle ilişkili $\mathrm{p}$ tane değişkeni bir araya getirerek az sayıda ilişkisiz ve kavramsal olarak anlamlı yeni değişkenler bulmayı, keşfetmeyi amaçlayan çok değişkenli bir istatistiktir (Büyüköztürk, 2007; Tavşancıl, 2002). Bu bağlamda, faktör analizi, verilerin küçültülmesi işlemini görmektedir (Özdamar, 2004). Faktör analizi, açımlayıcı (exploratory) ve doğrulayıcı (confirmatory) olmak üzere iki şekilde ele alınmaktadır. Açımlayıcı faktör analizi, maddeler arasındaki ilişki yapısını inceleyerek, ölçme aracının yapı geçerliğini keşfetmeye çalışmaktadır. Doğrulayıcı faktör analizi ise bazı ölçütler doğrultusunda açımlayıcı yöntemin iddia ettiği modeli sınamayı ve modelin uygunluğunu (model fit) test etmeyi amaçlamaktadır (Tabachnick ve Fidell, 2001). Açımlayıcı faktör analizi, ölçekteki maddelerin faktör yük değerlerine göre optimal boyutlandırmakta yapmaktadır. İncelenen maddelerin tümü tek boyutlu olabileceği gibi, bütün gibi düşünülen maddeler farklı alt boyutlarda da bulunabilmektedir. Ölçme aracına ilişkin elde edilen faktör yapısının uygunluğu doğrulayıcı faktör analizindeki bir takım ölçütler ile test edilebilmektedir. Modelin uygunluğuna test etmede kullanılan $X^{2}$ istatistiğinin tek başına yeterli gelmediği, aynı zamanda Ortalama Hataların Karekökü (Root Mean Square Error of Approximation; RMSEA), Karşılaştırmalı Uygunluk İndeksi (Comparative Fit Index; CFI) ve Uygunluk İndex (Goodness of Fit Index; GFI) ölçütlerinin de birlikte değerlendirilmesi önerilmektedir (Tabachnick ve Fidell; Kline, 2000;Yıldız ve Ergin, 2007). Temelde faktör analizi için örneklemin uygunluğu önemli görülmektedir. Örneklem uygunluğu Kaiser-Meyer-Olkin (KMO) ve Barlett testi ile sınanmaktadır. Ayrıca, faktör analizinin temel amaçlarından biri olan 
maddelere ilişkin yük değerinin tespiti de, ölçme aracındaki maddelerin birbirleri ile olan ilişki yapısının manidarlığını ortaya koymaktır (Büyüköztürk, 2002; Büyüköztürk, 2007). Söz konusu bu uyarlama çalışması, detayları belirtilen istatistiksel yöntemler ile incelenmiştir.

Açımlayıcı faktör analizi ve iç tutarlılık katsayısının tespiti için SPSS yazılımı, doğrulayıcı faktör analizinde ise Lisrel yazılımı kullanılmıştır.

\section{BULGULAR}

Veri seti öncelikle açımlayıcı faktör analizi ile incelenmiş, daha sonra elde edilen faktör yapısının geçerliğinin sınanması için de doğrulayıcı faktör analizi uygulanmıştır. Açımlayıcı faktör analizinin uygulanabilirliği KaiserMeyer-Olkin (KMO) ve Barlett testi ile analiz edilmiştir. Örneklem uygunluğunun belirleyicisi olan KMO değeri yüksek bir seviye ile .93 ve benzer şekilde Barlett Küresellik (Sphericity) testine ilişkin değer de manidar bulunmuştur $\left(\chi^{2}=3103.332 ; \mathrm{p} \cong .000\right)$. Veri seti faktör analizine tabi tutulmuştur. Faktör analizinde özdeğeri (eigenvalue) 1'in üzerinde olan faktörler dikkate alınmıştır. Faktör analizi ilk etapta ölçek yapısının iki alt ölçek altında toplanabileceğini tespit etmiştir. Analizde döndürme yöntemi olarak varimax dik döndürme yöntemi kullanılmıştır. Birinci alt faktöre ilişkin açıklanan varyans \%32.925 ve ikinci alt faktör için de açıklanan varyans \%7.856 olarak bulunmuştur. İki alt faktörün birlikte açıkladıkları varyans \%40.781 olarak elde edilmiştir. Ölçeğin orijinalinin tek boyutlu olduğu göz önünde bulundurularak, Türkçe uyarlama çalışmasındaki iki alt faktördeki maddeler isimlendirilmek üzere detaylı inceleme altına alınmıştır. Ayrıca, bu durum ölçeğin gerçek sahiplerine bildirilip görüş alınmak istenmiştir. Ancak, ölçekteki maddelerin bir bütün olarak sadece "internet bağımlılı̆̆ını" belirlemeye yönelik geliştirildiği dönütü ve inceleme sonucu da ayrı olarak alt faktörler altında toplanan maddelerin aslında benzer içerik taşıdıkları gözlemi ve de ikinci alt faktöre ilişkin açıklanan varyansın düşük bir değere (\%7.856) sahip oluşu, analizin tek faktör altında toplanması kararını oluşturmuştur. Ayrıca, ikinci alt faktörde açıklanan varyansın düşük olması, ilgili alt boyutun seslendirmesini de güçleştirmiştir. Bilindiği üzere, DSM-IV'te internet bağımlılığı madde bağımlılığı gibi ele alınmakta ve bağımlılı̆̆ın alt boyutlarına ilişkin seslendirme yine DSM-IV esasına göre yapılmaktadır. $\mathrm{Bu}$ gerekçelerden dolayı, özgün ölçek formundaki tek boyutluluğa paralel olarak uyarlama çalışması da genel bir isimlendirme ile "internet bağımlılığı" şeklinde sonuçlandırılmıştır.

Böylece, veri seti tek faktör altında açıklanmak üzere tekrar analize tabi tutulmuştur. Tek boyutluluk için yapılan faktör analizinde açıklanan varyans \%32.925 olarak tespit edilmiştir. Bu analize ilişkin faktör yük değerleri Tablo 1'de gösterilmiştir. 
Tablo 1. Tek boyutlu yapıdaki maddelerin faktör yük değerleri

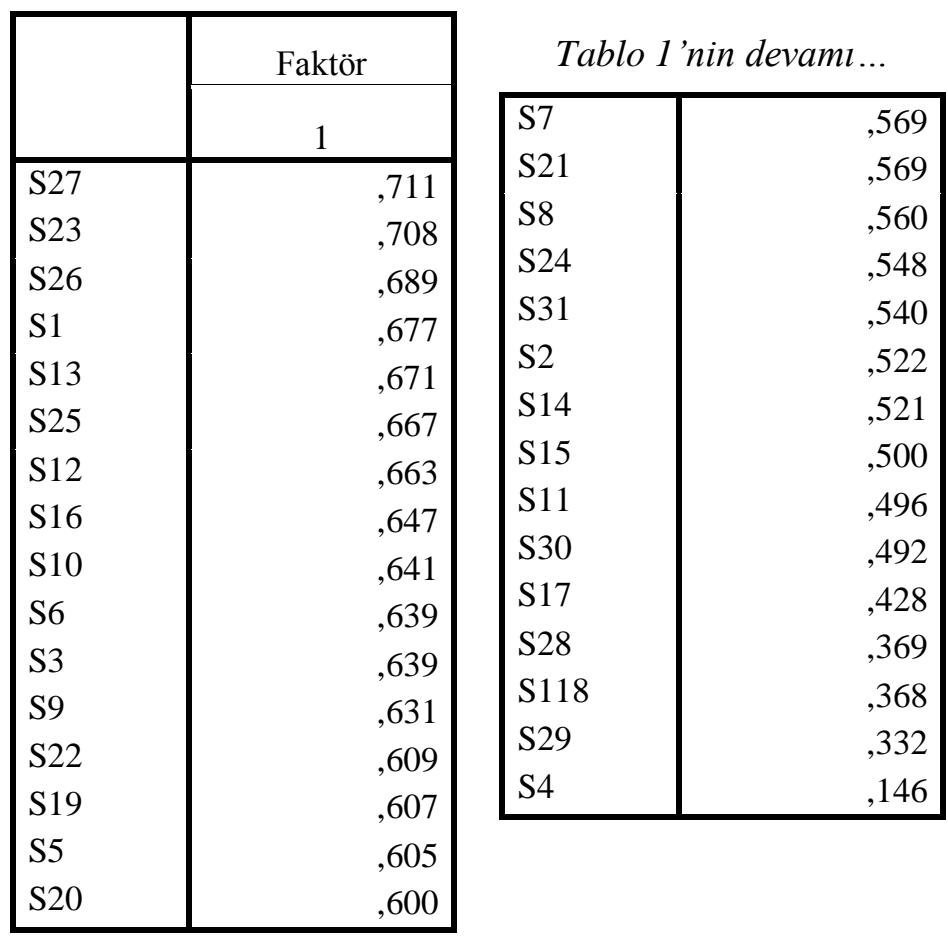

Tablo 1 incelendiğinde, dördüncü maddeye ait faktör yük değerinin 0.30 'dan düşük olduğu ve bu yönüyle dördüncü maddenin yapı geçerliği açısından tek boyutlu ölçeğe bir katkı sağlamadığı görülmüştür. Bu durum için de tekrar ölçeği geliştirenlerin görüşüne başvurulmuştur ve bu maddenin atılabileceği kararına varılmıştır. Böylece ölçek, Türkçe uyarlamada 30 maddeye indirgenmiştir. 30 maddeden oluşan Türkçe uyarlama ölçeği tekrar faktör analizine tabi tutulmuştur. Son kez faktör analizine tabi tutulan yapı \%33.959 açılanan varyans değeri ile sonuçlanmıştır ve maddelere ilişkin faktör yük değerleri Tablo 2'de gösterildiği gibidir. 
Tablo 2. IBÖ’'deki maddelere ilişkin faktör yük değerleri

\begin{tabular}{|l|r|}
\hline & Faktör \\
\cline { 2 - 2 } & 1 \\
\hline S27 &, 712 \\
S23 &, 711 \\
S26 &, 687 \\
S1 &, 678 \\
S13 &, 673 \\
S25 &, 669 \\
S12 &, 661 \\
S16 &, 646 \\
S6 &, 640 \\
S10 &, 639 \\
S3 &, 639 \\
S9 &, 632 \\
S22 &, 610 \\
S19 &, 606 \\
S5 &, 603 \\
\hline
\end{tabular}

Tablo 2 'nin devami...

\begin{tabular}{|l|l|}
\hline S20 &, 598 \\
S21 &, 568 \\
S7 &, 566 \\
S8 &, 562 \\
S24 &, 551 \\
S31 &, 538 \\
S2 &, 521 \\
S14 &, 521 \\
S15 &, 503 \\
S11 &, 498 \\
S30 &, 493 \\
S17 &, 424 \\
S28 &, 372 \\
S118 &, 367 \\
S29 &, 331 \\
\hline
\end{tabular}

Tablo 2'de belirtildiği üzere maddelere ilişkin yük değerleri .331 ile .712 arasında değişim göstermiştir. Bu durumda tüm maddelerin .30 kritiğinin üstünde bir değere sahip olduğu gözlenmiştir. Tek boyutlu yapıya ilişkin yı̆̆ılma grafiği de (scree plot) Şekil 1'de gösterilmiştir. 


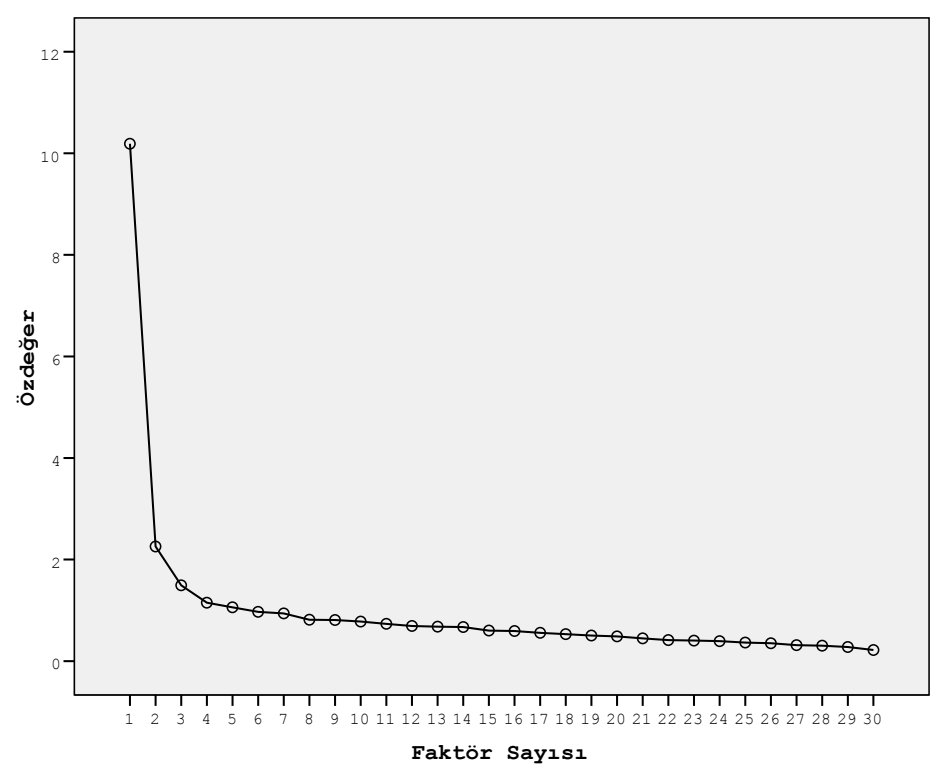

\section{Şekil 1. IBÖ̈'deki maddeler ilişkin yı ̌̆ılma grafiği}

Açımlayıcı faktör analizi sonucu 30 maddelik Türkçe ölçeğin geçerlik çalışması tamamlanmıştır. Ölçeğe ilişkin güvenirlik katsayısı da (cronbach alfa) .93 olarak tespit edilmiştir. Bu analizlerden sonra açımlayıcı faktör analizin elde ettiği yapı geçerliği doğrulayıcı faktör analizi (DFA) ile test edilmiş̧ir. Elde edilen modelin uygunluğu (fit of model); RMSEA (Root Mean Square Error Approximation), CFI (Comparative Fit Index) ve GFI (Goodness of Fit Index) uyum ölçütleri ile test edilmiştir. Söz konusu bu uyum ölçütlerinin modeli test etmede ideal ölçütler olabileceği düşünülmüştür. Yapılan analiz sonucu, modelin uygunluğuna ilişkin RMSEA değeri .075 olarak tespit edilmiştir. RMSEA değerinin sıfıra yaklaşması modelin uygun düzeyde olduğunu göstermektedir (Tabachnick, 2001; Brown ve Cudeck, 1993). Analiz sonucu CFI değerinin 0.79 ve GFI değerinin de 0.74 olduğu görülmüştür. İyi bir model için CFI ve GFI değerlerinin 1'e yaklaşması gerekmektedir. CFI ve GFI değerinin eşik sınırı .70 olabileceği düşünüldüğünde, çalışmada elde edilen değerlerin iyi bir seviyede olduğu kabul edilebilir. Tüm ölçütler göz önünde bulundurulduğunda, doğrulayıcı faktör analizi sonucu elde edilen tek faktörlü bir yapının iyi bir modele sahip olduğu savunulabilir. Doğrulayıcı faktör analizde yordanmaya çalışılan örtük değişken (latent variable) tek 
faktörlü bir yapıda bir bağımlı değişken ve örtük değişkeni açıklamaya çalışan ölçek maddeleri de bağımsız değişken olarak kabul edildiğinde, modele ilişkin diyagram (path diagram) Şekil 2'de gösterilmektedir.

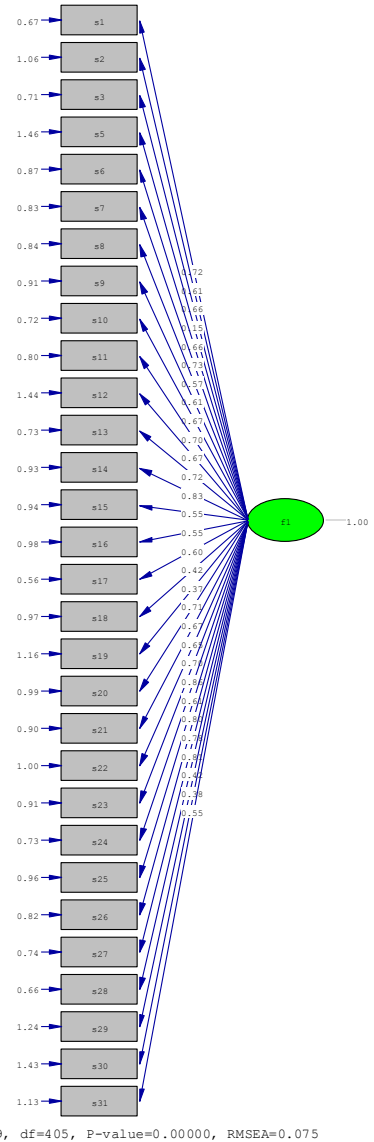

Şekil 2. Doğrulayıcı Faktör Analizine iliş̧kin diyagram

Şekil 2'de her bir maddenin örtük bağımlı değişken üzerindeki etki miktarları ve korelasyon katsayıları görülmektedir. Maddelere ilişkin korelasyon katsayılarının .15 ile .83 arasında değişim gösterdiği gözlenmiştir. Ayrıca, Şekil 2, modelin uygun olduğunu ve maddeler arasındaki korelasyonun iyi düzeyde olduğunu göstermektedir $\left(X^{2}=978.39\right.$; $\mathrm{p}<.01)$. Ancak, alanyazın $\mathrm{X}^{2}$ istatistiğinin tek başına iyi bir modelin 
habercisi olamayacağını bildirmektedir (Tabachnick 2001'den aktarma, Bentler, 1988; Kline, 2000). Bundan dolayı, uyum iyiliği ölçütlerinden RMSEA, CFI ve GFI değerleri de incelenmiştir. Araştırmada maddeler arasındaki korelasyonun ve 30 maddenin tek boyutla tanımlanmasının uygunluğu $\mathrm{X}^{2}$ ve RMSEA ölçütleri ile oldukça manidar bulunmuştur. Ayrıca, CFI ve GFI değerleri de iyi bir modelin göstergeleri olarak kabul edilebilir. Alanyazında ağırlıklı olarak, korelasyon ilişkisindeki yaklaşıma benzer şekilde, modele dair mükemmel bir ilişki için CFI ve GFI değerlerinin .90 'nın üstünde çıkması beklenmektedir. Daha genelleyici bir yaklaşım ile, CFI ve GFI değerlerinin mümkün mertebe 1 sınırına yaklaşması beklenmektedir. Ancak, .70'in altındaki değerler modeli iyi bir seviyeden aşağılara doğru düşürmektedir. Çalışmada Lisrel yazılımı ile elde edilen CFI ve GFI değerlerinin kabul sınırlarında olabileceği düşünülmüştür. Ancak, $X^{2}$ ve RMSEA değerlerindeki tutuculuğun CFI ve GFI'de görülememesi açımlayıcı faktör analizindeki \%33.295 açıklanan varyans değeri ile ilişkili olabileceği düşünülmüştür. Ayrıca, özgün ölçeğin tek boyutla tanımlanmasına karşın \%46.50 açıklanan varyans değerine sahip oluşu, ölçeğin geliştirildiği ülkedeki bireylerin interneti kullanım sıklığı ve bilgi-iletişim teknolojilerinin yaygınlığıyla ilişkilendirilebilir. Türkçe uyarlama çalışmasındaki örneklemin oluşumunda özellikle öğrencilerin internet hizmetine ücretsiz olarak sunulan BBAUM tercih edilmesine karşın bu öğrencilerin kaldığı yurt ortamlarında internete erişim imkânının olamayışının açıklanan varyans üzerinde etkili olabileceği düşünülmüştür. Ayrıca, diğer bazı sosyo-kültürel, sosyo-ekonomik ve sosyo-psikolojik faktörlerin de her iki çalışmadaki açıklanan varyans değerinin farklı oluşunda etkili olabileceği göz önünde bulundurulmalıdır. Ancak, çalışmada elde edilen açıklanan varyans değerinin .30'dan yüksek ve iç tutarlılık katsayısının da oldukça iyi bir düzeyde olması ölçeğin kullanılabilirliğini desteklemektedir. Zira, alanyazın, tek faktörlü ölçeklerde açıklanan varyansın $\% 30$ ve daha fazla olmasını yeterli görmektedir (Büyüköztürk, 2007). Bu gerekçelerden dolayı Türkçeye uyarlaması yapılan "İnternet Bağımlılık Ölçeği”nin tutarlı ve kullanışı olduğu savunulabilir. Ayrıca, açıklanan varyansın yüksek olması, ilgili kavram ya da yapının o denli iyi ölçüldüğünün bir göstergesi olarak yorumlanmamalıdır (Büyüköztürk, 2007).

Türkçe uyarlaması yapılan İnternet Bağımlılık Ölçeği 30 maddeden oluşmakta olup, özgün ölçekte bağımlılık taban puanı $(3 * 30) 90$ olarak belirlenmişti. Ancak, bu çalışmada eşik değer hesabı örneklemdeki yapıya uygun olarak hesaplanmıştır. Oysa özgün ölçek, her örneklem için genelleyici $(3 *$ madde sayısı) bir formülle eşik değerini hesaplamaktaydı; bu 
durumun örneklem denemelerinde farkl1lık göstereceği düşünülmüştür. Eşik değer hesaplamalarının her örneklem için ayrı bir şekilde hesaplanması daha gerçekçi karşılanmıştır. Yapı geçerliği ve güvenirliği tamamlanmış olan İnternet Bağımlılık Ölçeği'nden elde edilen madde toplamlarına ilişkin tanımlayıcı istatistikler Tablo 3'de gösterilmiştir:

Tablo 3. Ölçekten elde edilen toplam puanlara ilişkin tanımlayıcı istatistikler

\begin{tabular}{cccccc}
\hline \multirow{2}{*}{ Birey Sayı1 } & Minimum & Maksimum & $\bar{x}$ & Std. Hata & Std. Sapma \\
\hline 253 & 30.00 & 150.00 & 67.716 & 1.255 & 19.974 \\
\hline
\end{tabular}

Tablo 4'deki bulgulara göre, 253 bireyin ölçekten almış olduklara puan ortalamasının 67.716 ve puanlara ilişkin standart sapmanın 19.974 olduğu tespit edilmiştir. Örneklemdeki bireylerin ölçekten aldıkları toplam puana ilişkin dağılımın normallik durumu Kolmogorov-Smirnov testi ile sınanmıştır. Yapılan analize göre toplam puan değişkeni normal dağılım göstermiştir ( $p=.310)$. Bu durumda, internet bağımlılığındaki seviye (düşükorta-yüksek şeklinde), ortalama-standart sapma (düşük seviye); ortalama (orta seviye) ve ortalama + standart sapma (yüksek seviye) şeklinde hesaplanabilir. Ancak, veri setindeki bireylerin aynı evrenlerden gelememe şüphesi üzerine, veri seti parametrik olmayan kümeleme analizi ile detaylı bir şekilde incelenmiştir. İki aşamalı kümeleme analizi yöntemi ile, örneklemdeki heterojenlik durumu da hesaba katılarak, bağımlılık seviyesi daha gerçekçi bir şekilde ortaya konmuştur. Diğer şekliyle (ortalama \pm standart sapma; düşük-orta-yüksek) örneklemdeki uç bireylerin gözlenemeyeceği unutulmamalıdır. Ölçek formundan alınan toplam puanlar homojen olma durumlarına göre iki aşamalı kümeleme analizine tabi tutulmuş olup, her seviyedeki eşik değerler (cut-off) daha detaylı bir şekilde ortaya konabilmiştir. Kümeleme analizi, ölçekten alınacak toplam puanın, 30 - 60, $61-70,71-80,81-89$ ve 90 - üstü şeklinde kümelenmesini uygun görmüştür. Bu yolla, bağımlılık düzeylerinin detaylı bir şekilde ölçülmesi mümkün olabilmektedir. Yapılan analizde; 104 (\%41.10) bireyin $30-60$ puan aralığında, 43 bireyin (\%17) 61 - 70 puan aralığında, benzer şekilde 43 bireyin (\%17) 71 - 80 puan aralığında, 32 bireyin (\%12.64) 81 - 89 puan aralığında ve son olarak 31 bireyin de (\%12.26) 90 - üstü puan aralığında oldukları tespit edilmiştir. Bu veriler sşığında, 253 bireyden 31'inin internet bağımlısı olduğu tespit edilmiştir. Bununla birlikte 81 ve 89 puan aralığındaki bireylerin risk grubunu oluşturdukları düşüncesinin uygun olabileceği kabul edilmiştir. Bu durumda, 32 bireyin internet bağımlısı olma yolunda risk içerisinde oldukları söylenebilir. 


\section{TARTIŞMA ve SONUÇ}

Her türlü bağımlılıkta olduğu gibi internet bağımlılık türünün de, bireylerin üzerinde etkili olabileceği, özellikle de bireylerin eğitim-öğretim süreçlerinde etkililik düzeylerinin daha önemsenmesi gerektiği düşünülmektedir. Sosyalleşme sürecinde etkili olabilecek internet bağımlılığ 1 Esen, 2007; Şendağ ve Odabaş1, 2007), ögrencilerin akademik ve bireysel gelişimleri üzerinde de oldukça önemli bir etkiye sahip olabilmektedir (Young ve Case, 2004; Young, 2004). İnternet bağımlılığı, psikolojik bir rahatsızlıkla birlikte patolojik bir hastalık olarak da düşünülmektedir (Gönül, 2002; Bölükbaş, 2003; Young, 2004; Odabaş1oğlu ve diğ., 2007). Bu derece etkililiği söz konusu olan internet bağımlılığının bireylerdeki mevcudiyeti ve bu mevcudiyetin düzeyi, hem eğitimciler hem de klinisyenler tarafindan oldukça önemsenmektedir. Bundan dolayı, psikolojik test ve ölçeklerin yanı sıra, internet bağımlılığını araştırmaya yönelik ölçme araçları da geliştirilmektedir. $\mathrm{Bu}$ bağlamda, bu çalışma, ulusal alanyazına katkı sağlamayı ve bu konuda yeterli görülmeyen ölçme aracı eksikliğini gidermeyi hedeflemiştir.

İnternet bağımlılık ölçeğinin Türkçe uyarlamasına yönelik yapılan geçerlik - güvenirlik analizleri, alanyazın 1şığında değerlendirilmiş ve elde edilen değerlerin beklenen sınırlar içerisinde olduğu görülmüştür. Ölçeğin özgün formu tek boyutlu olarak elde edilmiş ve Türkçe uyarlamada da aynı yapı korunabilmiştir. Ölçeğe ilişkin yapı geçerliği ve boyutlandırma işlemleri açımlayıcı faktör analizi ile yapılmıştır. Yapı geçerliği ile önemli bir ilişkisi olduğu bilinen iç tutarlılık güvenirlik analizi de (Arıcak ve Ilgaz, 2007) yapılmış ve elde edilen alfa değerinin yüksek iç tutarlılığa işaret ettiği tespit edilmiştir $(\alpha=0.93)$. Uyarlama çalışmasındaki örneklem büyüklügünün uygunluğu $\mathrm{KMO}$ ve Barlett istatistiği ile onaylanmıştır (KMO $\left.=.93 ; X^{2}=3103.332, p \cong 0.000\right)$. Açımlayıcı faktör analizinde elde edilen modelin uygunluğu doğrulayıcı faktör analizi ile test edilmiştir. Alanyazın, doğrulayıcı faktör analizinde $\mathrm{X}^{2}$, RMSEA, CFI ve GFI ölçütlerinin uygun modelin belirleyicisi olduğunu belirtmiş (Tabachnick ve Fidell, 2001; Brown, 2006; Westorn ve Gore, 2006), bu çalışma için de söz konusu uyum ölçütleri dikkate alınmıştır. Uyum ölçütlerine ilişkin değerler ölçeğin tek faktör altında toplanabileceğini ve korelasyon katsayıları da ölçekteki maddelerin birbirleriyle ilişkili olduğunu göstermektedir.

Bireylerdeki tutum ve davranışların süreç içerisinde değişebileceği gerçeğinden yola çıkarak, geliştirilen ya da uyarlanan tüm ölçeklerin uzun vade geçerli ve güvenilir bir yap1 sergileyemeyeceği daima göz önünde bulundurulmalıdır. Bu bağlamda, uyarlaması yapılan İnternet Bağımlılık Ölçeği'nin de süreç içerisinde farklı örneklemler üzerinden yeniden yapı geçerliği ve güvenirlik çalışmalarının yapılması önemle önerilmektedir. 


\section{KAYNAKLAR}

Arıcak, O.T., Ilgaz, G. (2007). Açımlayıcı ve Doğrulayıcı Faktör Analizi ile Biyoloji Dersi Tutum Ölçeğinin Yap1 Geçerliliğinin İncelenmesi. Ĕ̆itim araştırmaları Dergisi, 28, 1-8.

Bentler, P.M. (1988). Comparative fit indexes in structural models. Psychological Bulletin, 107, 238-246.

Bölükbaş, K. (2003). "İnternet Cafeler ve İnternet Bağımlılı̆̆ı Üzerine Sosyolojik Bir Araştırma: Diyarbakır Örneği.” Yayınlanmamış yüksek lisans tezi, Dicle Üniversitesi Sosyal Bilimler Enstitüsü Sosyoloji Anabilim Dalı, Diyarbakır.

Büyüköztürk, Ş. (2002). Faktör Analizi: Temel Kavramlar ve Ölçek Geliştirmede Kullanımı. Eğitim Yönetimi Dergisi, 470-483.

Büyüköztürk, Ş. (2007). Sosyal Bilimler İçin Veri Analizi El Kitabı (7.Baskl). Ankara: PegemA Yayıncılık.

Brown, T.A. (2006). Confirmatory factor analysis: for applied research. New York: Guilford Press.

Browne, M.W., \& Cudeck, R. (1993). Alternative ways of assessing model fit. In K.A. Bollen \& J.S. Long (Eds.), Testing structural models. Newbury Park: Sage Publications.

Cao, F., \& Su, L. (2007). Internet addiction among chinese adolescents: prevalence and psychological features. Child: Care, Health and Development,33(3), 275-281.

Çöpür, M., Elmas, İ., Can, Y. (1995). Madde Bağımlılığı ve Antisosyal Kişilik. Kriz Dergisi, 3(1-2), 194-196.

Egger, O., \& Rauterberg, M. (1996). "Internet Behaviour and Addiction" Unpublished Master Thesis, Work \& Organisational Psychology Unit (IfAP), Swiss Federal Institute of Technology (ETH), Zurih.

Esen, B. K. (2007). Akran Baskisı ve Algilanan Sosyal Destek Değişkenlerine Göre Ergenlerde Internet Bağımlılı̆̆ının Yordanması. I.Uluslararası Bağımlılık Kongresi, İstanbul.

Gönül, A. S. (2002). Patolojik İnternet Kullanımı. Yeni Symposium, 40(3), 105-110.

Hall, A. S. \& Parsons, J. (2001). Internet addiction: college students case study using best practices in cognitive behavior therapy. Journal of Mental Health Counseling, 23(4), 312-327. 
Ju-Yu Y., Chih-Hung K., Cheng-Fang Y., Sue-Huei C., Wei-Lun C., \& Cheng-Chung C. (2008). Psychiatric symptoms in adolescents with internet addiction: Comparison with substance use. Psychiatry and Clinical Neurosciences, 62: 9-16.

Kaltiala-Heino, R., Lintonen, T., \& Rimpela, A. (2004). Internet addiction: potentially problematic use of the internet in a population of 12-18 year-old adolescents. Addiction Research and Theory, 12(1), 89-96.

Kim, S., \& Kim, R. (2002). A study of internet addiction: status, causes, and remedies. Journal of Korean Home Economics Association English Edition, 3(1).

Kline, P. (2000). Handbook of psychological testing (second edition). London and Newyork: Routledge Taylor \& Francis Group.

Laura A. N., \& Richard N. (2004). Development of a psychometrically sound internet addiction scale: a preliminary step. Psychology of Addictive Behaviors, Vol. 18, No. 4, 381-384.

Leung, L. (2004). Net-generation attributes and seductive properties of the internet as predictors of online activities and internet addiction. Cyberpsychology \& Behavior, 7(3).

Lim, J., Bae, Y., \& Kim, S. (2004). A Learning System for Internet Addiction Prevention. Proceedings of the IEEE International Conference on Advanced Learning Technologies (ICALT'04).

Mossbarger, B. (2008). Is internet addiction addressed in the classroom? A survey of psychology textbooks. Computers in Human Behavior, 24, 468-474.

Murali, V. \& George, S. (2007). Lost online: an overview of internet addiction. Advances in Psychiatric Treatment, 13, 24-30.

Nalwa, K., \& Anand, A. (2003). Internet addiction in students: a cause of concern. Cyberpsychology \& Behavior, 6(6).

Odabaşıoğlu, G., Öztürk, Ö., Genç, Y., Pektaş, Ö. (2007). On Olguluk Bir Seri İle İnternet Bağımlılı̆̆ 1 Klinik Görünümleri. Bağımlılık Dergisi, $8(1), 46-51$.

Özdamar, K. (2004). Paket Programlar ile İstatistiksel Veri Analizi 2 / Çok Değişkenli Analizler (Beşinci Baskı). Eskişehir: Kaan Kitabevi.

Simkova, B., \& Cincera, J. (2004). Internet addiction disorder and chatting in the czech republic. Cyberpsychology \& Behavior, 7(5). 
Şendağ, S., Odabaşı, F. (2007). İnternet Bă̆ımlılı̆̆ı: Çocukların Psikososyal Gelişimi Üzerindeki Etkileri. The Proceedings of International Educational Technology Conference, Near East University, North Cyprus.

Tabachnick, G.B., \& Fidell, L.S. (2001). Using multivariate statistics (fourth edition). USA: Allyon and Bacon Press.

Tavşancıl, E. (2002). Tutumların Ölçülmesi ve SPSS İle Veri Analizi. Ankara: Nobel Yayın.

Tezbaşaran, A. (1997). Likert Tipi Ölçek Geliştirme Kılavuzu (İkinci Baskı). Ankara: Türk Psikologlar Derneği Yayınları.

Tvedt, H. (2007). "Internet Use and Related Factors Among Fifth-Graders." Unpublished Master Thesis, Umeå Üniversitesi Psychology Department.

Vaugeois, P. (2006). Cyberaddiction: fundamentals and perspectives. Canada: Centre québécois de lutte aux dépendances.

Yellowlees, P., \& Marks, S. (2007). Problematic internet use or Internet addiction. Computers in Human Behaviour, 23.

Yen, J. Y., Yen, C. F., Chen, C. C., Chen, S. H. ve Ko, C. H. (2007). Family factors of internet addiction and substance use experience in taiwanese adolescents. Cyberpsychology \& Behavior, 10(3).

Yıldız, E., Ergin, Ö. (2007). Üst Bilişe Yönelimli Sınıf Çevresi Ölçeği-Fen (ÜBYSÇÖ-F)'in Türkçeye Uyarlanması: Geçerlik ve Güvenirlik Çalışması. Eğitim Araştırmaları Dergisi, 28, 123-133.

Young, K. S., \& Rodgers, R. (1998). The relationship between depression and internet addiction. Cyberpsychology \& Behavior, 1(1), 25-28.

Young, K.S. (2004). Internet addiction: a new clinical phenomenon and its consequences. American Behavioral Scientist, 48(4), 402-415.

Young, K. S., \& Case, C. J. (2004). Internet abuse in the workplace: new trends in risk management. Cyberpsychology \& Behavior, 7(1).

Zsolt D., Szeredi, B., \& Rózsa, S. (2008). The three-factor model of internet addiction: the development of the problematic Internet use questionnaire (PIUQ). Behavior Research Methods, 179, Budapest, Hungary.

Weston, R., \& Gore, Jr.P.A. (2006). A brief guide to structural equation modeling. The Counseling Psychologist, 34(5), 719-751. 
